\title{
Factors Associated with the Progression of Preeclampsia at Kinshasa University Clinics in Democratic Republic of Congo
}

\author{
Vangu Vangu Roland ${ }^{1,5}$, Rahma Rashid Tozin ${ }^{1}$, Mbuyi Muamba Jean Marie ${ }^{1}$, \\ Mokondjimobe Etienne, ${ }^{3,4}$, Mambueni Thamba Christophe ${ }^{3}$, Vangu Ngoma Dieudonné3, \\ Tsimba Vangu Andrien ${ }^{5}$, Makoso Nimi Blaise ${ }^{5}$, Mbungu Fuele Simon ${ }^{3}$, \\ Nkodila Natuhoyila Aliocha ${ }^{3,}$, Longo-Mbenza Benjamin ${ }^{1,2,3}$ \\ ${ }^{1}$ Départment of Gynécology and Obstétric, University of Kinshasa, Kinshasa, Democratic Republic of Congo \\ ${ }^{2}$ Department of Internal Medicine, Walter Sisulu University, Mthatha, South Africa \\ ${ }^{3}$ Department of Public Health, Lomo-University Reseach, Kinshasa, Democratic Republic of Congo \\ ${ }^{4}$ Department of Sciences, Universityof Marien Ngouabi, Brazzaville, Republic of Congo \\ ${ }^{5}$ Department of Internal Medecine, University of Président Joseph KASA-VUBU, Boma, Democratic Republic of Congo
}

Email address:

nkodilaaliocha@gmail.com (N. N. Aliocha)

*Corresponding author

\section{To cite this article:}

Vangu Vangu Roland, Rahma Rashid Tozin, Mbuyi Muamba Jean Marie, Mokondjimobe Etienne, Mambueni Thamba Christophe, Vangu Ngoma Dieudonné, Tsimba Vangu Andrien, Makoso Nimi Blaise, Mbungu Fuele Simon, Nkodila Natuhoyila Aliocha, Longo-Mbenza Benjamin. Factors Associated with the Progression of Preeclampsia at Kinshasa University Clinics in Democratic Republic of Congo. European Journal of Preventive Medicine. Vol. 8, No. 5, 2020, pp. 66-71. doi: 10.11648/j.ejpm.20200805.12

Received: August 6, 2020; Accepted: August 24, 2020; Published: September 25, 2020

\begin{abstract}
Background and aims: the progression of preeclampsia continues to increase in sub-Saharan Africa where care is inadequate. The objective of this study is to identify factors associated with the progression of preeclampsia at University Clinics of Kinshasa. Methods: This is a prospective and analytical study of 265 patients hospitalized at the Gynecology Service of the University Clinics of Kinshasa between January 1, 2006 and December 31, 2015. The clinical, biological, therapeutic and evolutionary characteristics were the parameters of 'interest. Cox regression in multivariate analyzes was generated to identify risk factors for progression to the $\mathrm{p}<0.05$ threshold. Results: The cumulative frequency of preeclapse decreased from $6.0 \%$ in the first year to $64.2 \%$ at the end of the study with periods of stagnation in the rate. Predictors of the progression of preeclampsia in the study population for $\mathrm{F}$ values equal to $2.86,2.10,3.57,3.23,2.81$ and 0.005 and an $\alpha$ risk equal at 0.009 ; $0.014 ; 0.006 ; 0.007 ; 0.005$ and 0.0060 .0005 , respectively, for age, level of education, occupation, SAP, DBP and figure 3 , led us to reject the null hypothesis of equality of means between progression and the lack of progression. In multiple cox regression, the risk of progression of preeclampsia was 3 times respectively in parturients aged $>35$ years (aRR: 2.57 95\% CI: 1.89-4.75), in female employees (aRR: 2.83 95\% CI: 1.97-4.46); this risk was 2 times respectively among academics, PAS and PAD elevated. Treatment under scheme 3, on the other hand, reduced the risk of progression 2 (aRR: 0.43 95\% CI: 0.28-0.63). Conclusion: the progression of pre-eclampsia could be linked to certain socio-demographic and clinical factors. The role played by the treatment regimen of amethyl Dopa + Nifedipine + Diazepam remains to be defined in this subgroup.
\end{abstract}

Keywords: Progression, Preeclampsia, Risk Factors, CUK

\section{Introduction}

Preeclampsia occupies an important place in the cardiovascular pathology associated with pregnancy, because of its frequency estimated at $20 \%$ of hypertensive pregnant women in the world [1-4] and its lethality which remains always high in developed countries [1, 2, 5-7] and even more in the African series [8]. In the African environment, late 
diagnosis, at the stage of obstetric complications, the inadequacy of the therapeutic indications and the insufficiency of resuscitation means explain the particular gravity of preeclampsia, which is one of the main causes of maternal and perinatal mortality [8].

Its progression in terms of incidence continues to increase. Several factors may explain this increase in the difficulties of access to health care for the population of pregnant women; the non-optimal application of the protocol by health professionals; and association with other pathologies such as malaria and the environment [9].

Early detection of women at risk for preeclampsia is considered a key to the development of tools to prevent the disease and its complications. In this context, several studies have been conducted but their results are insufficient or contradictory to effectively determine a predictive marker of the progression of pre-eclampsia in clinical practice [9]. Some risk factors have already been identified, in particular primiparae, multiple pregnancy, history of high blood pressure and maternal age $[10,11]$. Research on the environmental factors that make it possible to identify its progression appears to be increasingly important in modulating the disease $[12,13]$. From the confirmation of familial factors by certain cohort or family studies, mutations favoring pre-eclampsia have been identified [13, 14]. Although the exact time of onset and the mechanism of the disease remain uncertain, advances in pathophysiology research lead to the conclusion that the disease sets in well before 20 weeks of age $[13,15]$. The possible impacts after 20 WA could only accelerate the complications of preeclampsia. To study the influences of climatic factors on the occurrence of preeclampsia, it seems obvious to measure exposures before 20 weeks. However, to date no study has examined the impacts of these factors in the progression of the disease. The objective of this study is to identify factors associated with the progression of preeclampsia at the University Clinics of Kinshasa.

\subsection{Patients and Methods}

This study took place in the Gynecology Department of the University Clinics of Kinshasa. This is a prospective and analytical study concerning a continuous series of patients hospitalized in the Gynecology department between January 1, 2006 and December 31, 2015. The patients were received in the Gynecology emergency room where the first treatments were instituted. Depending on their clinical condition, their obstetrical situation and the progress observed under treatment, they were kept in the delivery room for the needs of parturition for follow-up. After childbirth, postnatal follow-up was carried out for mothers and live newborns. To include the patients, we retained two criteria defined by group II of the classification of the National High Blood Pressure Education Program of United States [16]: arterial hypertension onset after the twentieth week of amenorrhea (based on the history and data from antenatal consultations) and proteinuria assessed by the test strip method and / or a test in urine collected over 24 hours We did not include patients who were lost to follow-up and those who were in a coma.

The data were collected on a computerized form containing the following parameters: medical and surgical history, prenatal consultations, clinical examination on entry, additional examinations carried out, medical treatment instituted, progress under treatment, childbirth, postpartum follow-up.

\subsection{Statistical Analyzes}

Evaluation, validation (univariate analysis, frequency, percentage, Pearson's Chi-square test, Student's t-test) and multivariate analysis (discriminant analysis, multiple cox regression) of the data were respectively performed.

Pearson's Chi-square test compared the percentages of the incidence of progression of preeclampsia (dependent variable) and socio-demographic and clinical factors.

Cox regression in multivariate analyzes was generated to identify risk factors for progression and degree of influence by calculating the adjusted RR and $95 \%$ confidence intervals.

The discriminant analysis was able to classify patients into different groups of progression during the study period (progression, decrease or constant in the frequency of a preeclampsia) according to their characteristic. Wilk's Lambda coefficient was calculated to obtain dimensions or components (factors) in the number of groups minus one. Indeed, multivariate discriminant analysis is considered as an intermediate statistical method at the limit of the field of modeling and that of multidimensional investigation without validity test according to the following equation.

$$
\mathrm{S}\left(\mathrm{t}_{\mathrm{r}}\right)=\prod_{\mathrm{r}=1}^{\mathrm{n}} \frac{(\mathrm{n}-\mathrm{r})^{\delta_{\mathrm{r}}}}{(\mathrm{n}-\mathrm{r}+1)^{\delta_{\mathrm{r}}}}
$$

With $\mathrm{S}(\mathrm{t} 0)=1$ and $\mathrm{t} 0=0$.

Where $\mathrm{P}=$ probabilities / proportion of colorectal cancer incidence and mortality.

The value of Probability $\mathrm{P}<0.05$ was considered the threshold of statistical significance. All statistical analyzes were performed with IBM * SPSS (Statistical Package for Social Sciences) software on Windows version 24 (New York, USA).

\section{Results}

Frequency of Progression of Preeclampsia

During the years of follow-up, 170 of the 265 women followed had seen their disease progressed, ie an overall frequency of $64.2 \%$ of disease progression (Figure 1).

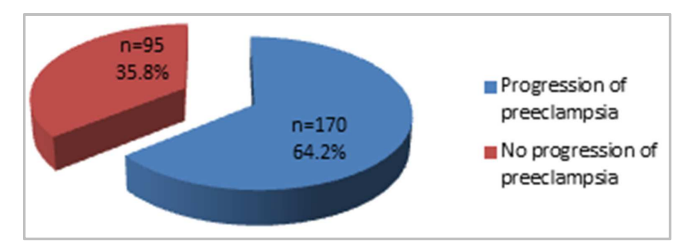

Figure 1. Frequency of progression of preeclampsia in the study population.

Evolution of preeclampsia over the years

The cumulative frequency of preeclapsis increased from $6.0 \%$ in the first year to $64.2 \%$ at the end of the study with 
periods of stagnation in the frequency) (Figure 2).

The socio-demographic characteristics of the progression of preeclampsia are shown in Table 1. It shows that women with progression of preeclampsia were older than those without progression of preeclampsia $(p=0.017)$. The frequency of academics $(p=0.023)$, employment $(p=0.021)$, obesity $(p=$ 0.032 ), and history of preeclampsia (0.026) were significantly higher in women with progression of preeclampsia. The mean values of BMI, SBP, and DBP were significantly higher in women with progression of preeclampsia.

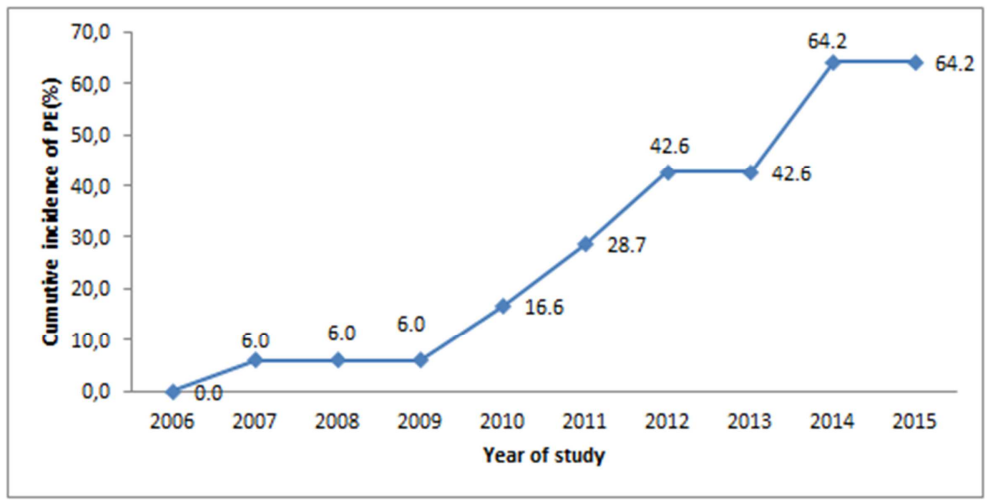

Figure 2. Evolution of preeclampsia over the years.

Table 1. Sociodemographic characteristics and progression of $P E$.

\begin{tabular}{|c|c|c|c|c|}
\hline Variables & Over all $n=265$ & Progression of $P E n=170$ & No progression of $P E n=95$ & $\mathbf{p}$ \\
\hline Age & $31.8 \pm 5.68$ & $35.2 \pm 5.8$ & $30.9 \pm 5.8$ & 0.017 \\
\hline$<20$ years & $4(1.5)$ & $1(0.6)$ & $3(3.2)$ & \\
\hline $20-35$ years & $178(67.2)$ & $110(64.7)$ & $68(71.6)$ & \\
\hline$>35$ years & $83(31.3)$ & $59(34.7)$ & $24(25.3)$ & \\
\hline Season & & & & 0.168 \\
\hline Rain & $150(56.6)$ & $92(54.1)$ & $58(61.1)$ & \\
\hline Dried & $115(43.4)$ & $78(45.9)$ & $37(38.9)$ & \\
\hline Primary & $72(27.2)$ & $45(26.5)$ & $27(28.4)$ & \\
\hline Secondary & $96(36.2)$ & $55(32.4)$ & $41(43.2)$ & \\
\hline University & $97(36.6)$ & $70(41.2)$ & $27(28.4)$ & \\
\hline Profession & & & & 0.021 \\
\hline Unemployed & $203(76.6)$ & $124(72.9)$ & $79(83.2)$ & \\
\hline Employment & $62(23.4)$ & $46(27.1)$ & $16(16.8)$ & \\
\hline Parity & & & & 0.333 \\
\hline Primiparous & $107(40.4)$ & $68(40.0)$ & $39(41.1)$ & \\
\hline Multiparous & $51(19.2)$ & $36(21.2)$ & $15(15.8)$ & \\
\hline Large multiparous & $21(7.9)$ & $10(5.9)$ & $11(11.6)$ & \\
\hline Gesture & & & & 0.774 \\
\hline Primigest & $76(28.7)$ & $48(28.2)$ & $28(29.5)$ & \\
\hline Paucigest & $86(32.5)$ & $55(32.4)$ & $31(32.6)$ & \\
\hline Multigest & $67(25.3)$ & $46(27.1)$ & $21(22.1)$ & \\
\hline Large multigest & $36(13.6)$ & $21(12.4)$ & $15(15.8)$ & \\
\hline BMI & $28.9 \pm 3.9$ & $30.8 \pm 4.0$ & $25.1 \pm 3.8$ & 0.015 \\
\hline Overweight & $117(44.2)$ & $69(40.6)$ & $48(50.5)$ & 0.076 \\
\hline Obesity & $104(39.2)$ & $69(40.6)$ & $35(36.8)$ & 0.032 \\
\hline SBP & $174.3 \pm 19.1$ & $192.7 \pm 17.2$ & $171.1 \pm 21.8$ & 0.024 \\
\hline DBP & $114.9 \pm 10.5$ & $124.1 \pm 9.3$ & $111.3 \pm 12.2$ & 0.035 \\
\hline \multicolumn{5}{|l|}{ Antecedent } \\
\hline PE & $66(24.9)$ & $45(26.5)$ & $21(22.1)$ & 0.026 \\
\hline Caesaraen & $38(14.3)$ & $25(14.7)$ & $13(13.7)$ & 0.487 \\
\hline Therapeutic scheme 1 & $96(36.2)$ & $62(36.5)$ & $34(35.8)$ & 0.510 \\
\hline Therapeutic scheme 2 & $81(30.6)$ & $54(31.8)$ & $27(28.4)$ & 0.336 \\
\hline Therapeutic scheme 3 & $22(8.3)$ & $10(5.9)$ & $12(12.6)$ & 0.049 \\
\hline Therapeutic scheme 4 & $66(24.9)$ & $44(25.9)$ & $22(23.2)$ & 0.368 \\
\hline
\end{tabular}

Predictors of the progression of preeclampsia in the study population For s $\mathrm{F}$ values of 2.86, 2.10, 3.57, 3.23, 2.81 and
0.005 and an $\alpha$ risk equal to $0.009 ; 0.014 ; 0.006 ; 0.007 ; 0.005$ and 0.0060 .0005 , respectively, for age, level of education, 
occupation, PAS, PAD and diagram 3, we are led to reject the null hypothesis of equality of means between the progression and the absence of progression of preeclampsia in the study population.

For the variables pregnancy, cesarean section, and scheme
1, their univariate Wilks lambda values are equal to 1 and indicate an equal mean between the progression and the absence of progression of preeclampsia in the study population. For the other variables, we note clearly different group means and interclass variability (Table 2).

Table 2. Tests of equality of group means.

\begin{tabular}{|c|c|c|c|c|c|}
\hline Facteurs & Lambda de Wilk's & $\mathbf{F}$ & ddI1 & dd12 & p-value \\
\hline Age & 0.989 & 2.862 & 1 & 263 & 0.009 \\
\hline Level of study & 0.992 & 2.097 & 1 & 263 & 0.014 \\
\hline Profession & 0.987 & 3.570 & 1 & 263 & 0.006 \\
\hline Parity & 0.999 & 0.163 & 1 & 263 & 0.687 \\
\hline Gesture & 1.000 & 0.003 & 1 & 263 & 0.958 \\
\hline BMI & 0.999 & 0.309 & 1 & 263 & 0.579 \\
\hline $\mathrm{PE}$ & 0.998 & 0.618 & 1 & 263 & 0.433 \\
\hline SBP & 0.988 & 3.226 & 1 & 263 & 0.007 \\
\hline DBP & 0.989 & 2.811 & 1 & 263 & 0.005 \\
\hline Proteinuria & 0.993 & 1.948 & 1 & 263 & 0.164 \\
\hline Edema & 0.991 & 2.356 & 1 & 263 & 0.126 \\
\hline gestationnal age at admission WA & 0.998 & 0.564 & 1 & 263 & 0.453 \\
\hline Therapeutic scheme 1 & 1.000 & 0.012 & 1 & 263 & 0.912 \\
\hline Therapeutic scheme 2 & 0.999 & 0.319 & 1 & 263 & 0.573 \\
\hline Therapeutic scheme 4 & 0.999 & 0.240 & 1 & 263 & 0.624 \\
\hline
\end{tabular}

Canonical discriminant functions

In the canonical function of the variables, it is shown that if the socio-demographic variables increase in the environment, there is a significant increase in progression. In quadrant 4 , there is an increase in the decrease in preeclampsia.

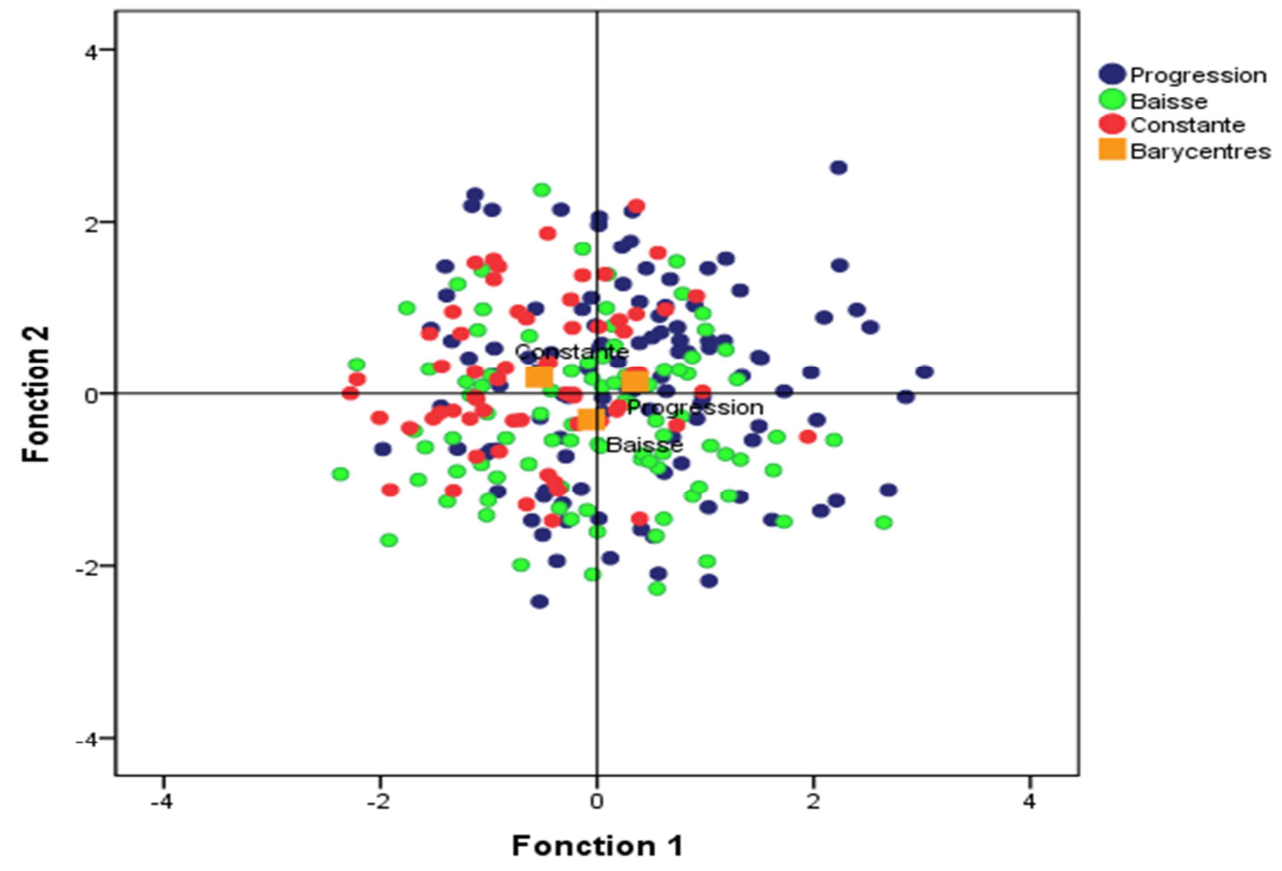

Figure 3. Canonical discriminant function.

The combined intra-group correlations between discriminant variables and the variables of the standardized canonical discriminant functions are ordered by absolute sizes of the correlations within the function. Variables with a larger absolute correlation size in function 1 were discriminated against as factors in the progression of preeclampsia.
Table 3. Coefficients of standardized canonical discriminant functions.

\begin{tabular}{lll}
\hline \multirow{2}{*}{ Facteurs } & Function & \\
\cline { 2 - 3 } & $\mathbf{1}$ & $\mathbf{2}$ \\
\hline Age & 0.419 & 0.016 \\
Level of study & 0.595 & -0.215 \\
Profession & -0.038 & 0.014 \\
Parity & -0.214 & -0.251 \\
\hline
\end{tabular}




\begin{tabular}{lll}
\hline \multirow{2}{*}{ Facteurs } & \multicolumn{2}{l}{ Function } \\
\cline { 2 - 3 } & $\mathbf{1}$ & $\mathbf{2}$ \\
\hline Gesture & 0.547 & 0.321 \\
BMI & -0.399 & -0.018 \\
PE & 0.525 & -0.345 \\
Caesaraen & -0.392 & -0.328 \\
SBP & -0.290 & 0.316 \\
DBP & 0.377 & 0.072 \\
Proteinuria & -0.039 & 0.276 \\
Edema & -0.004 & 0.214 \\
Gestationnal age & -0.315 & 0.284 \\
Therapeutic scheme 1 & 0.134 & -0.216 \\
Therapeutic scheme 2 & 0.185 & 0.356 \\
Therapeutic scheme 3 & -0.023 & -0.098 \\
\hline
\end{tabular}

In Table $4,71.9 \%$ of the variables correlate with $33 \%$ the progression of preeclampsia $(\mathrm{R} 2=0.33)$.

Table 4. Coefficients of the classification of the function of progression of preeclampsia.

\begin{tabular}{lllll}
\hline Function & Eigenvalue & \% of variance & \% cumulative & $\begin{array}{l}\text { Canonical } \\
\text { correlation }\end{array}$ \\
\hline 1 & 0,122 & 71,9 & 71,9 & 0,330 \\
2 & 0,048 & 28,1 & 100,0 & 0,214 \\
\hline
\end{tabular}

In radomized multiple cox regression, the risk of progression of preeclampsia was 3 times respectively in parturients aged $>35$ years (aRR: 2.57 95\% CI: 1.89-4.75), in employees (aRR: 2.83 95\% CI: 1.97-4.46); this risk was 2 times respectively among academics, PAS and PAD elevated. On the other hand, the treatment under scheme 3 reduced the risk of progression 2 (aRR: 0.43 95\% CI: 0.28-0.63).

Table 5. Relative risk of progression of preeclampsia.

\begin{tabular}{lll}
\hline Factors & Ajusted RR (95\%CI) & p \\
\hline Age $>35$ years & $2.57(1.89-4.75)$ & 0.011 \\
Employment & $2.83(1.97-4.46)$ & 0.006 \\
Level study university & $1.93(1.06-3.52)$ & 0.032 \\
High SBP & $2.01(1.09-4.25)$ & 0.016 \\
High DBP & $2.02(1.09-4.45)$ & 0.019 \\
Therapeutic cheme 3 & $0.43(0.28-0.63)$ & 0.006 \\
\hline
\end{tabular}

\section{Discussion}

The objective of this study was to identify the risk factors associated with the progression of preeclampsia at the University Clinics of Kinshasa between 2006 and 2015. Preeclampsia has become a rare condition in developed countries thanks to early management. On the other hand, the monitoring of pregnancies by qualified health personnel, the screening of high-risk pregnancies and patient information have helped to reduce this pathology [17]. However, it remains frequent in our developing countries and this prevalence is almost increasing in Sub-Saharan Africa [1820]. This progression of preeclampsia is linked to several factors which have as a common denominator the low socioeconomic level of the populations. In our series, the major problem found was the high frequency of women with a rate of progression of preeclampsia, indeed, the insufficiencies noted in the prenatal follow-up did not make it possible to slow down this progression. At the national level, these figures will have to be revised upwards again, because most studies only allow us to identify cases received in the referral structures. This means that the prevalence in rural or inaccessible areas is poorly appreciated. In addition, we found in our series a certain variation in the frequency of preeclampsia according to the years. This aspect has been reported in studies by Dao et al. [20] and Elongi et al. [21] who suggested that there would be an association between the characteristics of the years of follow-up, among others humidity, low temperatures in some years and the risk of preeclampsia.

Among the risk factors for preeclampsia, this study found that age over 35 multiplied the risk of progression by 3 , unlike the results reported by Akpadza et al [22] who found the risk under 18 years. To our knowledge, this age group corresponds to the period during which the female genital activity peaks [23], hence the risk of disease progression.

In this study, the incidence of chronic hypertension was significantly associated with the progression of preeclampsia $(\mathrm{RR}=2.01$ for PAS and $R R=2.02)$. This observation is in agreement with the study by Sibaï et al. [24] who consider long-term cardiovascular morbidity as one of the maternal complications of PE. Based on the systematic review by Duckitt et al. [25] the clinical profile of these women with 2 history of PE and the presence of comorbidities such as chronic hypertension, would increase their risk of developing another PE. However, our results did not demonstrate that the combination of recurrent $\mathrm{PE}$ and the presence of traditional risk factors for cardiovascular disease has an aggravating effect on the risk of developing severe preeclampsia with or without adverse criteria during subsequent pregnancy. It would be legitimate to think that the variable "taken ASA with or without LMWH" could have had an attenuating effect on the degree of severity of recurrent PE, and consequently on the associated perinatal and maternal morbidity.

The impact of a treatment certainly deserves to be considered from a clinical point of view. Thus with the relative risk is $\mathrm{RR}=0.43$ and a $95 \%$ confidence interval $\mathrm{CI}=$ $(0.28 ; 0.63)$, the amethyl Dopa + Nifedipine + Diazepam scheme reduces the relative risk of progression by half. The literature is not unanimous on the dosages of a given in this regimen; more studies are needed to converge views on the issue. In their review of the regimen for managing preeclampsia, Henderson et al. [26] report results of the same order as ours on the relative risk $(\mathrm{RR}=0.46)$ with $\mathrm{CI}=[0.22$; 0.95 ] to $95 \%$ corresponding to a significant result. They also report this association starting the first prodromal episode is beneficial for perinatal health outcomes in women at high risk for preeclampsia.

\section{Conclusion}

Our work has shown that the progression of preeclampsia could be linked to certain sociodemographic and clinical factors. The role played by the treatment regimen of amethyl Dopa + Nifedipine + Diazepam remains to be defined in this 
subgroup. Women at greater risk of progression to preeclampsia appear to have a distinct clinical profile with preeclampsia defined as severe. Traditional risk factors for cardiovascular disease such as chronic hypertension are associated with this progression. These observations can be important in establishing the clinical history of the patient in early pregnancy and ultimately reducing the progression of preeclampsia.

\section{Author's Contributions}

RVV and ANN designed and analyzed the statistical data for the study. MTC, VND, TVA, MNB, and MFS contributed to the data collection. RRT, MMJM, ME and LMB supervised the study. All authors have read and approved the final and revised version of the manuscript.

\section{Conflict of Interest}

The authors declare no conflict of interest.

\section{Acknowledgements}

We thank all who participated in the study.

\section{References}

[1] Abalos E, Cuesta C, Grosso A, Chou D, Say L. Global and régional estimates of pre-eclampsia an eclampsia: a systematic review. Eur J Obstet Gynecol Reprod Biol. 2013; 170: 1-7.

[2] Laghzaoui M. Epidémioogie, morbidité, mortalité de la prééclampsie et éclampsie. J Gynécol.

[3] Obstét Biol Reprod. Paris. 2010; 39: S1-S342.

[4] Maroufatou. Prise en charge et pronostic de l'éclampsie en réanimation polyvalente au $\mathrm{CHU}$.

[5] Tchaou BA, Salifou k, Hounkponou FM. Prise en charge de la preeclampsia severe dans l'Hôpital Universitaire de Parakou (Bénin). Publication Med Afr Noire. 2012; 17: 2.

[6] Abdoul AD, Moussa D, Magatte M. Profil épidémiologique et prise en charge de l'éclampsie au Sénégal: à propos de 62 cas. Pan Afr Maed J. 2013; 16: 83.

[7] Pottecher T. Réanimation des formes graves de prééclampsie. J Gynecol Obstet, Biol Reprod 2001; 30: 121-32.

[8] Magnin G, Vequeau Goua V, Prurat O, Prene F. La prééclampsie sévère précoce: comment gérer le conflit d'intérêt foeto-maternel. J Gynecol Obstet Biol Reprod 2000; 29: $230-3$

[9] Liu, L., Zhang, M., Min, X. \& Cai, L. Low Serum Levels of ABCA1, an ATP-Binding Cassette Transporter, Are Predictive of Preeclampsia. Tohoku J. Exp. Med. 2015; 236: 89-95.

[10] Lechtermann, C. et al. Maternal vitamin D status in preeclampsia: seasonal changes are not influenced by placental gene expression of vitamin D metabolizing enzymes. PloS One 2014; 9: e105558.
[11] Abimanyu, B. The role of angiogenic factors in pre-eclampsia. Pregnancy Hypertens. 2014; 4: 246.

[12] Mandò, C. Maternal and fetal HLA-G 14 bp gene polymorphism in pregnancy-induced hypertension, preeclampsia, intrauterine growth restricted and normal pregnancies. J. Matern.-Fetal Neonatal Med. Off. J. Eur. Assoc. Perinat. Med. Fed. Asia Ocean. Perinat. Soc. Int. Soc. Perinat. Obstet 2015; 1-6.

[13] Kobayashi, H. The Impact of Maternal-Fetal Genetic Conflict Situations on the Pathogenesis of Preeclampsia. Biochem. Genet. 2015; doi: 10.1007/s10528-015-9684-y. Beltran, A., Wu, J. \&

[14] Laurent, O. Associations of Meteorology with Adverse Pregnancy Outcomes: A Systematic Review of Preeclampsia, Preterm Birth and Birth Weight. Int. J. Environ. Res. Public. Health 2013; 11: 91-172.

[15] Lisonkova, S. et al. Maternal morbidity associated with earlyonset and late-onset preeclampsia. Obstet. Gynecol. 2014; 124 771-781.

[16] National high blood pressure education programm. Report of working group on high blood pressure in pregnancy. Am J Obstet Gynecol 2000; 183 (suppl 1): S1-S22.

[17] Ducarme G, Herrnberger S, Pharisien I et al. Eclampsie: étude rétrospective de 16 cas. Gynecol Obstet Fertil. 2009; 37 (1): 11-17.

[18] Bèye M D, Diouf I, Bah M, Ndoye Diop M, Kane O, Sall Ka B. Prise en charge Hellp syndrome en réanimation à Dakar. Ann Fr Anesth Reanim. 2006; 25 (3): 291-295.

[19] Cissé CT, Faye Diémé ME, Ngabo D et al. Indications thérapeutiques et pronostiques de l?éclampsie au CHU de Dakar. J Gynecol Obstet Biol Reprod. 2003; 32 (3 pt 1): 239245 .

[20] Dao B. L'éclampsie: Aspects actuels et particularités au CHU de Dakar. 1990. Dakar. These Med n 9.

[21] Elongi JP, Tandu B, Spitz B, Verdonck F. Influence de la variation saisonnière sur la prévalence de la prééclampsie à Kinshasa. Gynecol Obstet Fertil. 2011; 39 (3): 132-135.

[22] Akpadza K, Baeta S, Kotor K. T, Hodonou A. K. S. L'éclampsie a la clinique de gynecologie-obstetrique du C. H. U Tokoin-Lome (Togo). Med. Afr. Noire. 1996; 43 (3): 166-9.

[23] Takongmo S, Binam F, Simeu CH, Ngassa P, Kouam L, Malonga E. Aspects thérapeutiques des péritonites génitales au CHU de Yaounde (Cameroun). Méd Afrique Noire. 2000; 47 (1): 19-21.

[24] Sibai B, Dekker G, Kupferminc M. Pre-eclampsia. Lancet. 2005 Feb 26-Mar 4; 365 (9461): 78599.

[25] Duckitt K, Harrington D. Risk factors for pre-eclampsia at antenatal booking: systematic review of controlled studies. BMJ. 2005; 330 (7491): 565.

[26] Henderson J. T. et al. Low-dose aspirin for the prevention of morbidity and mortality from preeclampsia. Technical report, U. S. Preventive Services Task Force, 540 Gaither Road, Rockville, MD 20850, 2014. 